of a screening method as an adjunct to the standard interview was outlined by Dr R. Caplan (St George's Hospital Medical School). This technique relies on the identification and use of the potential expatriate's coping mechanisms and those of the spouse, based on the premise that current strategies can predict future adaptive behaviour. $\operatorname{Dr} \mathrm{S}$. McKeown (Oxford University Department of Psychiatry) said that breakdown is a predictable and normal response to excessive pressure and that it does not necessarily mean permanent weakness or disability in the expatriate, who may be capable of dealing effectively with other demands in different circumstances.

REFERENCES

'LANIER, A. R. (1979) Selecting and preparing personnel for overseas transfers. Personnel Journal, March, 160-3.

${ }^{2}$ Brown, G. W. \& HarRIs, T. (1978) Social Origins of Depression: A Study of Psychiatric Disorder in Women. London: Tavistock Publications.

\title{
Collaboration between Psychiatric Case-Registers
}

\author{
JoHn K. Wing, Professor of Social Psychiatry, MRC Social Psychiatry Research Unit, Institute of Psychiatry, London
}

There are now six psychiatric case-registers covering areas in England, two in Scotland and one in Wales. All record the contacts made by patients or clients from a defined geographical area with specified medical and social services. This information is stored in a linked and cumulative file so that the care of any individual or group can be followed over time and the patterns of care established. The geographical base allows rates to be calculated and epidemiological research to be conducted.

Registers vary a good deal in the services they cover and in the details of their collection methods, but there is a central core of roughly comparable information. The directors and technical staff of eight registers, encouraged by the Department of Health and Social Security, therefore decided to adopt common definitions and procedures in order to produce a basic set of tables, so that at least some aspects of local services could be compared across areas and with the figures for England, Scotland and Wales.

The first such report has now been produced. It provides socio-demographic information about each area and statistics of in-patients, day care, out-patients and other forms of care for the period 1976 to 1981.

There are substantial socio-demographic differences, varying from inner conurban areas with declining populations (Camberwell, Salford), through medium-sized industrial cities with more or less average population indices (Cardiff, Nottingham, Southampton), to relatively attractive areas with increasing populations (Oxford and Worcester). The eighth register (Aberdeen) is difficult to fit into this scheme because of its mixture of far-flung rural hinterland and rapid industrial growth. It also shares, with Scotland, an in-patient rate twice that of England and $W$ ales.

In general, the data suggest that three kinds of factor should be taken into account when considering local rates of contact with services. The first is the way that services have developed over the preceding twenty years or so. The second is the extent to which the population is growing or decreasing in size, which may suggest differential in- or out-migration. The third is the pattern of socio-economic characteristics, particularly indices of social isolation, poverty and ethnicity. National rates are not necessarily suitable for local planning.

It is hoped to bring out regular reports in future and to improve both the coverage and the detail of the data provided, particularly of non-hospital services. Individual registers will contribute sections on services of particular local interest. Another promising development is the creation of case-registers in other European countries, notably Denmark, Holland, Italy and West Germany. Most of these have used British registers as a model and it should eventually be possible to provide a much broader comparison of services.

The first report ${ }^{1}$ is available from $\mathrm{Mr}$ C. Jennings, Southampton Psychiatric Case Register, Knowle Hospital, Fareham, Hants, PO17 5NA; price $£ 2.50$. Cheques should be made payable to 'The University of Southampton'.

RBFERENCE

'Gibbons, J., Jennings, C. \& Wing, J. K. (1984) Psychiatric Care in Eight Register Areas. 